\title{
Modulation of Secretory Leukoprotease Inhibitor Gene Expression in Human Bronchial Epithelial Cells by Phorbol Ester
}

\author{
Muneharu Maruyama, ${ }^{\star}$ John G. Hay, ${ }^{\star \ddagger}$ Kunihiko Yoshimura, ${ }^{\star}$ Chin-Shyan Chu, ${ }^{*}$ and Ronald G. Crystal ${ }^{\star \ddagger}$ \\ *Pulmonary Branch, National Heart, Lung, and Blood Institute, National Institutes of Health, Bethesda, Maryland 20892; and ${ }^{\ddagger}$ Division \\ of Pulmonary and Critical Care Medicine, Cornell University Medical College, New York 10021
}

\section{Abstract}

Secretory leukoprotease inhibitor (SLPI), a 12-kD nonglycosylated serine antiprotease, helps to protect the epithelial surface of the airways from the destructive capacity of neutrophil elastase. Based on the recognition that SLPI levels can increase in the presence of airway inflammation, we hypothesized that inflammatory stimuli should modulate the expression of the SLPI gene in airway epithelial cells. To evaluate this, the modulation of SLPI gene expression with various inflammatory stimuli was evaluated in the HS-24 human bronchial epithelial cell line. After preliminary studies showed that several inflammatory mediators enhanced SLPI messenger RNA (mRNA) levels, PMA was used as a model inflammatory stimulus. PMA significantly increased the level of 0.7-kb SLPI mRNA transcripts in HS-24 cells in a dose- and time-dependent fashion and increased the amount of SLPI protein in the culture supernatant. Nuclear run-on analyses showed that the SLPI gene transcription rate increased approximately twofold after PMA stimulation. Transfection studies using fusion genes composed of fragments of up to $1.2 \mathrm{~kb}$ of the $5^{\prime}$ flanking sequence of the SLPI gene and a luciferase reporter gene demonstrated potent promoter activity in the 131-bp segment (-115 to +16 relative to the transcription start site), and all longer segments up to $1.2 \mathrm{~kb}$, whereas smaller segments showed low promoter activity. An 18-bp element ( -98 to -115$)$, in a region with homology to PMA-responsive regions in the Moloney murine leukemia virus enhancer and the IL-8 gene, was shown to be of importance in the level of transcription of the SLPI gene. However, this element was not responsible for the upregulation of SLPI gene expression by PMA. Evaluation of HS-24 cells in the presence of actinomycin D demonstrated that SLPI mRNA transcripts were very stable and became more so in the presence of PMA. Thus, SLPI gene expression in airway epithelial cells can be upregulated by an inflammatory stimulus, and this modulation is regulated at both the transcriptional and posttranscriptional levels. These mechanisms of SLPI upregulation likely play a role in defending the epithelial surface in the local milieu of inflammatory lung disease. (J. Clin. Invest. 1994. 94:368375.) Key words: protease inhibitor $\cdot$ transcription $\cdot 5^{\prime}$ flanking region $\cdot$ neutrophil elastase $\cdot$ mRNA

Address correspondence to Ronald G. Crystal, Pulmonary Branch, Building 10, Room 6D03, National Institutes of Health, Bethesda, MD 20892.

Received for publication I April 1993 and in revised form 31 March 1994.

The Journal of Clinical Investigation, Inc.

Volume 94, July 1994, 368-375

\section{Introduction}

Secretory leukoprotease inhibitor (SLPI), ${ }^{1}$ a $12-\mathrm{kD}$ nonglycosylated serine antiprotease, is found in fluids lining mucosal surfaces, including those of the respiratory tract (1-4). SLPI inhibits several serine proteases, but with an association rate constant for neutrophil elastase (NE) of $\sim 10^{7} \mathrm{M}^{-1} \mathrm{~s}^{-1}$ and the ability to inhibit proteolysis at the neutrophil-substrate interface, the principal physiologic function for SLPI is likely to be protection of local epithelial surfaces against NE (4-7). In the human lung, immunohistochemical studies have demonstrated SLPI in serous cells of submucosal tracheal and bronchial glands and in nonciliated cells of the bronchial and bronchiolar epithelium $(2,3,8)$. Evaluation of fluid lining the airway epithelium of the human lung has demonstrated that SLPI provides substantial protection to the large airway epithelium of the human lung against $\mathrm{NE}(4,9,10)$.

Based on the knowledge of the role of SLPI in protecting the epithelial surface of the large airways, the present study focuses on evaluating whether the SLPI gene can be upregulated by inflammatory stimuli. There are several indirect reasons to believe that this may be the case. First, the sequence of the 5' flanking region of the SLPI gene contains promoter elements observed in most regulated genes, such as CAAT and TATA boxes, and putative binding sites for the nuclear transcription factors AP-1 and AP-2, binding motifs known to be responsive to inflammatory stimuli $(11-14)$. Second, there is evidence in humans that SLPI levels increase in inflammatory states. For example, the levels of SLPI are increased in the serum of adults with pneumonia $(5,15,16)$ and in the respiratory epithelial lining fluid of neonates with pneumonia (17). Finally, SLPI is in the class of antiproteases that inhibit serine proteases. The other major member of this class in humans is $\alpha 1$-antitrypsin ( $\alpha 1 \mathrm{AT})$, a well-known acute phase reactant $(4,18,19)$. The $\alpha 1 \mathrm{AT}$ gene is expressed in hepatocytes and mononuclear phagocytes, and these cells secrete more $\alpha 1 \mathrm{AT}$ in response to inflammatory processes $(4,20)$.

To evaluate the concept that the SLPI gene can be upregulated by inflammatory stimuli, we studied the ability of various inflammatory mediators to modulate the expression of the SLPI gene in the HS-24 bronchial epithelial cell line, a cell known to express the SLPI gene (21). Using PMA as a model of these inflammatory stimuli, the data demonstrate that inflammatory stimuli upregulated SLPI gene expression in airway epithelial cells by stimulating the $5^{\prime}$ flanking region of the SLPI gene to

Abbreviations used in this paper: $\alpha 1 \mathrm{AT}, \alpha 1$-antitrypsin; CAT, chloramphenicol acetyltransferase; CMV, cytomegalovirus; GAPDH, glyceraldehyde-3-phosphate dehydrogenase; MoMLV, Moloney murine leukemia virus; NE, neutrophil elastase; RSV, Rous sarcoma virus; SLPI, secretory leukoprotease inhibitor. 
enhance the transcription rate of the SLPI gene, as well as by enhancing SLPI messenger RNA (mRNA) stability.

\section{Methods}

Cell culture. HS-24 human bronchial squamous carcinoma cells (provided by W. Ebert, Thoraxklinikum, Heidelberg-Rohrbach, Germany) (21) and K562 erythroleukemia cells (CCL 243; American Type Culture Collection, Rockville, MD) were maintained in RPMI 1640 with 25 $\mathrm{mM}$ Hepes, $\mathrm{pH} 7.4,2 \mathrm{mM}$ glutamine, $100 \mu \mathrm{g} / \mathrm{ml}$ gentamicin [all from Gibco/Bethesda Research Laboratories, Gaithersburg, MD], and $10 \%$ FBS. BET-1A human bronchial epithelial cells transformed by SV40 virus (22) were cultured in serum-free LHC-9 medium with $25 \mu \mathrm{g} / \mathrm{ml}$ Fungizone, $25 \mu / \mathrm{ml}$ penicillin, and $25 \mu \mathrm{g} / \mathrm{ml}$ streptomycin (all from Biofluids Inc., Rockville, MD). HeLa cervical carcinoma cells (ATCC CCL 2), T84 colon adenocarcinoma cells (ATCC CCL 248), HT29 colon adenocarcinoma cells ( ATCC HTB 38), and HFL1 human diploid lung fibroblasts (ATCC CCL 153) were maintained in DMEM (BioWhittaker Inc., Walkersville, MD) supplemented with $10 \%$ FBS, $2 \mathrm{mM}$ glutamine, $50 \mathrm{U} / \mathrm{ml}$ penicillin, and $50 \mu \mathrm{g} / \mathrm{ml}$ streptomycin (all from Biofluids Inc.). All experiments were carried out when the cells were 80-90\% confluent except K562 cells, which were used during exponential growth $\left(5-10 \times 10^{5} / \mathrm{ml}\right)$.

Inflammatory stimuli. To evaluate the response of SLPI gene expression in bronchial cells to inflammatory stimuli, HS-24 cells were incubated alone or for $24 \mathrm{~h}$ with $1,000 \mathrm{U} / \mathrm{ml}$ human recombinant IL-6 (Genzyme Corp., Boston, MA), $25 \mathrm{U} / \mathrm{ml}$ human recombinant IL-1 $\beta$ (Collaborative Research Inc., Bedford, MA), $200 \mathrm{U} / \mathrm{ml}$ human recombinant TNF- $\alpha$ (Genzyme Corp.), 100 nM PMA (Sigma Chemical Co., St. Louis, MO) or $10 \mu \mathrm{g} / \mathrm{ml}$ LPS (Sigma Chemical Co.), all on three separate occasions. SLPI mRNA levels were evaluated by Northern analysis as described below. After this initial evaluation, all further experiments were carried out with PMA as the model inflammatory stimulus.

SLPI mRNA transcript levels. In the majority of studies, unless otherwise indicated, the levels of SLPI mRNA transcripts and, as a control, glyceraldehyde-3-phosphate dehydrogenase (GAPDH) mRNA transcripts were evaluated by Northern analysis (23). Total cellular RNA was isolated by the guanidinium thiocyanate- $\mathrm{CsCl}$ gradient method (24). RNA (10 $\mu \mathrm{g} /$ lane) was subjected to formaldehyde-agarose gel electrophoresis, transferred to a nylon membrane (Nytran; Schleicher and Schuell Inc., Keene, NH), hybridized with a ${ }^{32}$ P-labeled SLPI or GAPDH cDNA probe generated by the random priming method (25), and quantified using a PhosphorImager (Molecular Dynamics, Sunnyvale, $\mathrm{CA}$ ). The SLPI probe ( $\mathrm{pPB} 135$ ) was a full-length 0.6-kb human SLPI cDNA (11) and the GAPDH probe (pPB312) was a human 1.0-kb GAPDH cDNA clone encompassing the protein coding sequence (26).

Modulation of SLPI gene expression in HS-24 cells. To evaluate the dose-dependency of PMA-induced modulation of SLPI gene expression, HS-24 cells were stimulated with various concentrations of PMA (0$100 \mathrm{nM}$ ) for $24 \mathrm{~h}$. To determine the time dependence of SLPI gene expression, the cells were incubated for various times $(1-48 \mathrm{~h})$ in the presence of $100 \mathrm{nM}$ PMA. After incubation, total cellular RNA was isolated, and the levels of SLPI mRNA transcripts and, as a control, GAPDH mRNA transcripts were evaluated by Northern analysis as described above. The mRNA levels of SLPI and GAPDH were quantified using a PhosphorImager, and the data expressed as -fold (mean of three separate experiments) over the resting levels.

The transcription rate of the SLPI gene was examined by nuclear transcription run-on analysis (27). Nuclei were isolated from $5 \times 10^{7}$ resting or PMA-stimulated cells (100 nM; 1,3 , and $12 \mathrm{~h}$ ), and incubated with $5 \mathrm{mM}$ ATP, $2 \mathrm{mM}$ CTP, $2 \mathrm{mM}$ UTP, $250 \mu \mathrm{Ci}$ of $\left[\alpha-{ }^{32} \mathrm{P}\right] \mathrm{GTP}$ ( $>400 \mathrm{Ci} / \mathrm{mmol}$; Amersham Corp., Arlington Heights, IL) and $700 \mathrm{U} /$ ml RNase inhibitor (RNasin; Promega Corp., Madison, WI) to label actively transcribed RNA. RNA was recovered by the acid guanidinium thiocyanate-phenol-chloroform method (28) using RNAzol B (Tel-Test
Inc., Friendswood, TX), purified by Sephadex G-50 column chromatography ( 5 Prime $\rightarrow 3$ Prime, West Chester, PA) and hybridized to excess amounts $(5 \mu \mathrm{g})$ of DNA targets (see below) immobilized on nylon membranes. The membranes were then washed, exposed to RNase A $(5 \mu \mathrm{g} / \mathrm{ml})$ and RNase $\mathrm{T}_{1}(5 \mathrm{U} / \mathrm{ml})$, followed by proteinase $\mathrm{K}(50 \mu \mathrm{g} /$ $\mathrm{ml}$ ) (all from Boehringer Mannheim, Indianapolis, IN), and evaluated by a PhosphorImager. The DNA targets included plasmids containing a genomic clone for the SLPI gene (pPB133), an IL-8 cDNA (pPB248) and a human GAPDH cDNA (pPB312) (29), or, as a negative control, the plasmid pUC19 (Gibco/Bethesda Research Laboratories). The relative transcription rate of the SLPI gene after PMA stimulation, compared with the resting rate, was quantified using a PhosphorImager and expressed as -fold over the resting levels in four individual experiments.

To estimate the stability of SLPI mRNA transcripts, HS-24 cells were incubated alone or with PMA ( $100 \mathrm{nM}, 12 \mathrm{~h})$, and exposed to actinomycin D (5 $\mu \mathrm{g} / \mathrm{ml}$; Sigma Chemical Co.) for 4, 8, 12, and $16 \mathrm{~h}$ $(n=4)$. Total cellular RNA was extracted, and SLPI mRNA levels were evaluated by Northern analysis as described above and quantified using a PhosphorImager.

SLPI protein released by bronchial epithelial cells. To quantify the amount of SLPI protein released by the HS-24 cells, supernatants of resting and PMA-stimulated $(0.1-100 \mathrm{nM}) \mathrm{HS}-24$ cells $(n=3$ at each dose) were evaluated with a specific double-antibody sandwich ELISA compared with a purified recombinant SLPI standard (9).

Promoter activity of SLPI 5' flanking sequences. Transfection vectors containing fusion genes of 5 ' flanking region sequences of the SLPI gene and a luciferase reporter gene were constructed from a pUC8derived vector (pCMV-luciferase) (30). The SLPI promoter region, a 1,244-bp fragment spanning -1228 to +16 [numbering based on the reported sequence of SLPI gene by Abe et al. (11)], was prepared by polymerase chain reaction with plasmid pPB225 (a 1.4-kb PstI fragment containing SLPI gene exon 1 and 5' flanking region) as a template, and SLPI gene-specific primers (SLPIS5, $5^{\prime}$-ATTACTCGAGCTGCAGCCTCAAACTCCTGGGC-3'; and SLPIAS1, 5'-ATGTAAGCTTGGCAGGAGTGACTCTGATGGC-3' ${ }^{\prime}$ ). It was then cloned into a luciferase expression vector (pSL1228L) by replacing the cytomegalovirus (CMV) promoter in a pCMV-luciferase expression plasmid between unique XhoI and HindIII sites. Sequentially deleted fragments of the SLPI gene 5 ' flanking region (starting from $-802,-383,-115,-97$, $-79,-61$, and -43 to +16 ) were prepared in a similar manner. Based on the knowledge that the sequence between -98 and -115 may contain a cis-active element important for transcription (see Results), this sequence was deleted from the three longer constructs pSL1228L, pSL802L, and pSL383L to produce plasmids pSL1228LD, pSL802LD, and PSL383LD. This was achieved by site-directed mutagenesis using Transformer ${ }^{\mathrm{TM}}$ reagents (Clontech Laboratories, Palo Alto, CA), an oligonucleotide spanning but not including the 18-bp segment (SLPI1S, 5'CTCCTTGGTGTCAGGATTTCCCTGCTTATGCAATAGTAGCT-3') and oligonucleotides (SLPI5S for pSL1228L, 5'-GTGCACCATACATCGATCTGCAGCCTCAAAC-3'; SLPI7S for pSL802L, 5'GTGCACCATACATCGATGCTGCTTTCC-3'; SLPI9S for pSL383L, 5'-GTGCACCATACATCGATAAGTCTCAGCAGG-3') to mutate the unique XhoI site at the $5^{\prime}$-end of the flanking sequences $(31)$. The sequences of the SLPI 5 ' flanking region inserts of all vectors were confirmed by the dideoxy chain-termination method (32). The Rous sarcoma virus (RSV) long terminal repeat promoter-luciferase construct (pRSVL) (33) was used as the positive control, and promoterless luciferase plasmid (pLuc0) as the negative control (34).

HS-24 cells were transfected by electroporation (35). Cells were removed by trypsin, washed twice and resuspended in Dulbecco's phosphate-buffered saline (Gibco/Bethesda Research Laboratories) $\left(10^{7}\right.$ cells in $0.8 \mathrm{ml})$. Each luciferase expression plasmid vector $(15 \mu \mathrm{g})$ and a CMV promoter chloramphenicol acetyltransferase (CAT) expression plasmid [5 $\mu \mathrm{g}$; pCMV-CAT (29); as an internal control] were added to the cell suspensions. Electroporation was carried out at $300 \mathrm{~V}, 5.0$ $\times 10^{-4} \mathrm{~F}$ (Gene Pulser; Bio-Rad, Richmond, CA), and HS-24 cells were maintained in culture media at $37^{\circ} \mathrm{C}$ for $48 \mathrm{~h}$. To evaluate the 
A.

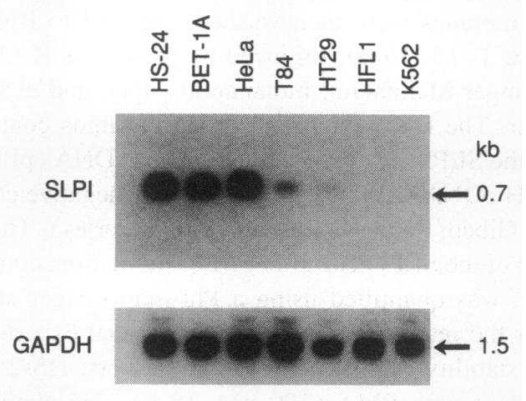

B.

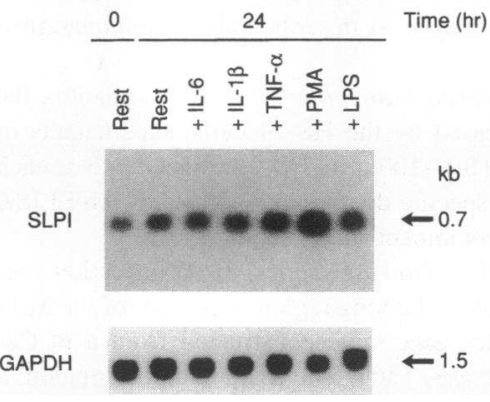

Figure 1. SLPI gene expression in human epithelial cells. (A) SLPI gene expression in various cell lines. Shown are Northern analyses of the SLPI mRNA transcripts (top), and GAPDH mRNA transcripts (bottom), in various cell lines. Data shown left to right are HS-24 bronchial squamous carcinoma cells, BET-1A bronchial epithelial cells, HeLa cervical carcinoma cells, T84 colon adenocarcinoma cells, HT29 colon adenocarcinoma cells, HFL1 diploid lung fibroblasts, and K562 erythroleukemia cells. The sizes of mRNA transcripts are indicated. $(B)$ Effect of inflammatory mediators on SLPI gene expression in HS-24 bronchial epithelial cells. Data shown are Northern blot analyses of RNA (10 $\mu \mathrm{g} /$ lane) from resting cells and cells after exposure for $24 \mathrm{~h}$ to IL-6 (1,000 $\mathrm{U} / \mathrm{ml}), \mathrm{IL}-1 \beta(25 \mathrm{U} / \mathrm{ml})$, TNF- $\alpha(200 \mathrm{U} / \mathrm{ml})$, PMA (100 nM), and LPS $(10 \mu \mathrm{g} / \mathrm{ml})$. The blots were hybridized with a ${ }^{32}$ P-labeled SLPI cDNA probe (top) and a GAPDH probe (bottom). The sizes of mRNA transcripts are indicated. Note that the exposure in $B$ is less than that in $A$ to better appreciate any up or down regulation of the SLPI gene.

effects of PMA on reporter gene expression, PMA (100 nM) was added to culture media $24 \mathrm{~h}$ before harvesting the transfected cells.

To measure reporter gene expression, cells were retrieved by scraping, washed, and resuspended in $200 \mu \mathrm{l}$ of lysis buffer ( $100 \mathrm{mM}$

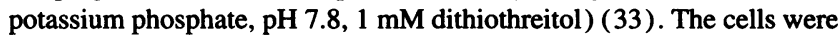
then lysed by three freeze-thaw cycles and centrifuged, and $50 \mu \mathrm{l}$ of supernatant was evaluated for luciferase activity using Monolight 2010 luminometer (Analytical Luminescence Laboratories, San Diego, CA) (29). The protein concentration of supernatants was measured by the Bradford method (36) (Bio-Rad protein assay; Bio-Rad) with bovine serum albumin as a standard. CAT activity was measured by standard methods (37). Levels of luciferase expression were normalized by CAT activity and are reported relative to the expression of PRSVL (defined as $100 \%$ ). To evaluate the relative increase in SLPI gene promoter activity after PMA stimulation, luciferase expression was normalized to the total protein concentration.

Statistical analyses. All data are presented as mean \pm SEM and comparisons were made using the two-tailed $t$ test, or for multiple comparisons analysis of variance with Fisher's correction.
A.
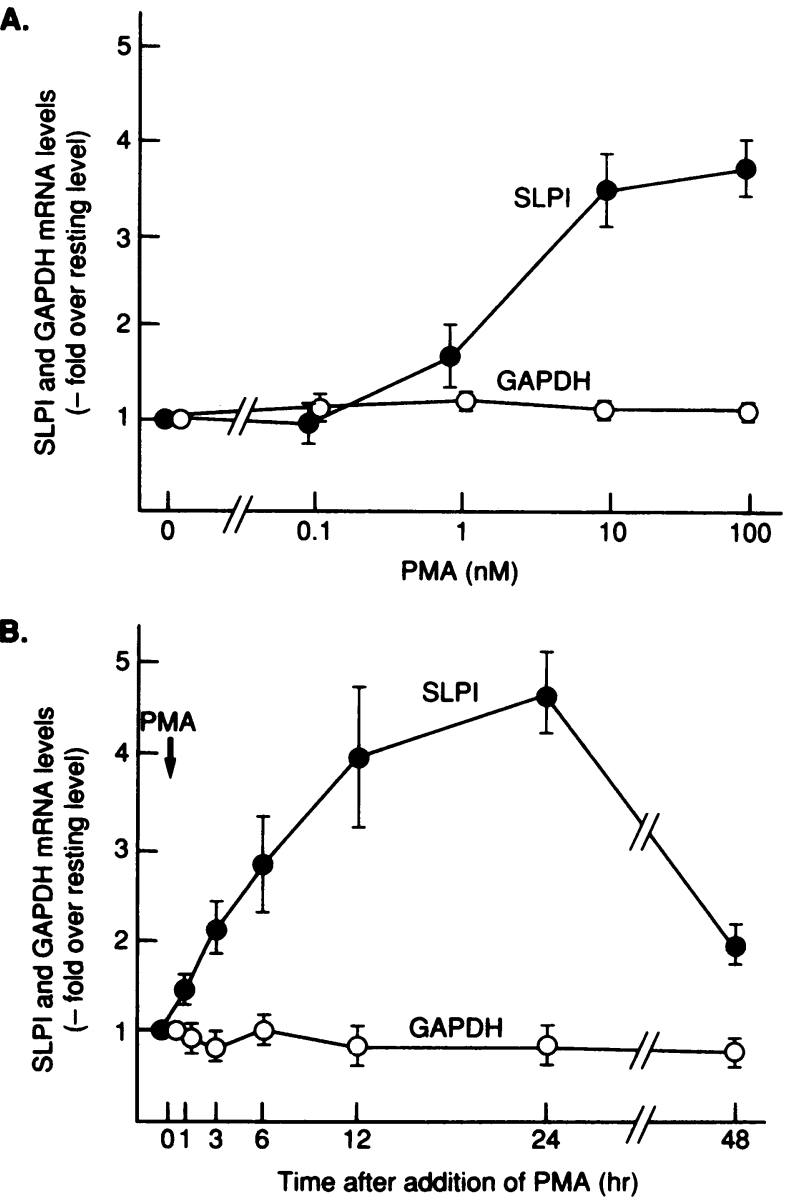

Figure 2. SLPI mRNA levels in HS-24 cells after exposure to PMA. $(A)$ Expression of SLPI mRNA $(\bullet)$ and GAPDH mRNA $(O)$ in response to increasing amounts of PMA in HS-24 cells. HS-24 cells were exposed to PMA (0.1-100 nM) for $24 \mathrm{~h}$. (B) Time course of SLPI mRNA ( $\bullet$ ) and a GAPDH mRNA $(O)$ expression before and at various times after exposure to PMA (100 nM). Total cellular RNA extracted from HS24 cells was evaluated by Northern analyses and quantified using a PhosphorImager. The data are presented as the mean \pm SEM of the -fold increase over the time 0 value from three separate experiments.

\section{Results}

SLPI gene expression in various cell lines. Consistent with the knowledge that SLPI protein is found in airway and cervical epithelial cells, HS-24 bronchial squamous carcinoma cells, BET-1A human bronchial epithelial cells, and HeLa cervical carcinoma cells all expressed 0.7-kb SLPI mRNA transcripts at high levels (Fig. 1 A). Cells of colon origin, T84 and HT29, expressed the mRNA transcripts at moderate to low levels. SLPI mRNA transcripts were not detected in HFLl human lung fibroblasts and K562 erythroleukemia cells, even after long exposure of the autoradiograms. Control GAPDH mRNA transcripts were expressed in similar amounts in all cell lines. Based on this data, all subsequent studies were carried out with HS-24 cells as a model of human bronchial epithelial cells.

Modulation of SLPI gene expression by inflammatory stim$u l i$. The level of SLPI mRNA transcripts increased mildly with 24-h culture without addition of any mediators (Fig. $1 \mathrm{~B}$ ). Importantly, SLPI mRNA levels increased significantly with 


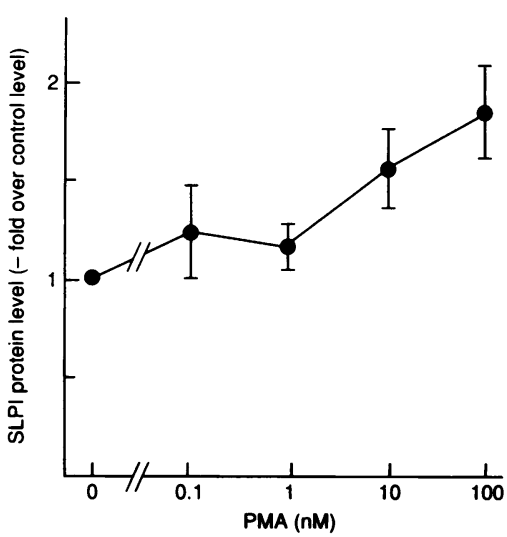

Figure 3. Amounts of SLPI protein in culture supernatants of HS-24 cells after stimulation with PMA. HS-24 cells $\left(10^{6}\right.$ cells $/ 100$-mm tissue culture dish) were grown in RPMI 1640 with $10 \%$ FBS for $48 \mathrm{~h}$. The cells were washed extensively with PBS and then cultured in fresh RPMI 1640 with $10 \%$ FBS in the presence of the indicated concentration of PMA for an

(0.1-100 $\mathrm{nM}$ )additional $24 \mathrm{~h}$. SLPI protein levels were quantified with a specific double-antibody sandwich ELISA.

exposure to TNF- $\alpha$ and PMA, and at a lesser extent to LPS. Neither IL-6 nor IL-1 $\beta$ had a significant effect. In contrast to SLPI mRNA transcripts, none of the inflammatory stimuli modulated GAPDH transcript levels in HS-24 cells. In the context of the high level of enhancement of SLPI expression in HS-24 cells with PMA, this model inflammatory stimulus was chosen for all subsequent studies.

PMA induced HS-24 cells to increase the levels of SLPI mRNA transcripts in a dose- and time-dependent fashion (Fig. 2). PMA-induced upregulation of SLPI gene expression was observed at low ( $1 \mathrm{nM})$ to high ( $100 \mathrm{nM})$ levels of PMA. In contrast, the level of GAPDH mRNA transcripts in the same cells did not change with increasing concentrations of PMA. After a fixed dose of PMA ( $100 \mathrm{nM}$ ) stimulation, SLPI mRNA transcript levels increased by $1 \mathrm{~h}$, to its maximum at $24 \mathrm{~h}$, and remained elevated at $48 \mathrm{~h}$. In contrast, GAPDH mRNA transcript levels were constant during the same period.

Consistent with the increase in SLPI mRNA transcript levels, SLPI protein concentrations in the supernatants released by HS-24 cells showed a dose-dependent increase as the PMA concentrations increased (Fig. 3). Supernatants from HS-24 cells stimulated with 100 nM PMA showed approximately twofold higher concentration of SLPI protein $(19.6 \mathrm{ng} / \mathrm{ml}) \mathrm{com}$ pared with those from resting cells $(10.8 \mathrm{ng} / \mathrm{ml})(P<0.05)$.

Evaluation of 5' transcription of the SLPI gene. Nuclear run-on analyses demonstrated that resting HS-24 cells actively transcribed the SLPI gene (Fig. 4). After PMA stimulation, the transcription rate of the SLPI gene increased apparently twofold $(P<0.05)$ at $1 \mathrm{~h}$ and then did not change significantly for 12 $h$. In contrast, the transcription rate of the IL-8 gene dramatically increased after PMA stimulation, but dramatically fell to values close to baseline by $12 \mathrm{~h}$.

To evaluate possible cis-acting DNA sequences relevant to transcriptional regulation of SLPI gene expression, sequentially deleted 5' flanking region fragments of the SLPI gene were linked to a luciferase reporter gene and evaluated in HS-24 cells (Fig. 5). This analysis demonstrated low activity until segments up to -115 bp $5^{\prime}$ to the transcription start site were included. With increasing lengths of $5^{\prime}$ flanking region up to $-1228 \mathrm{bp}$, the relative transcription rate varied, but remained in the $10 \%$ to $17 \%$ of the RSV promoter control rate. In the context of a dramatic increase between -97 and -115 , this 18 bp likely includes an important cis-control element relevant to expression

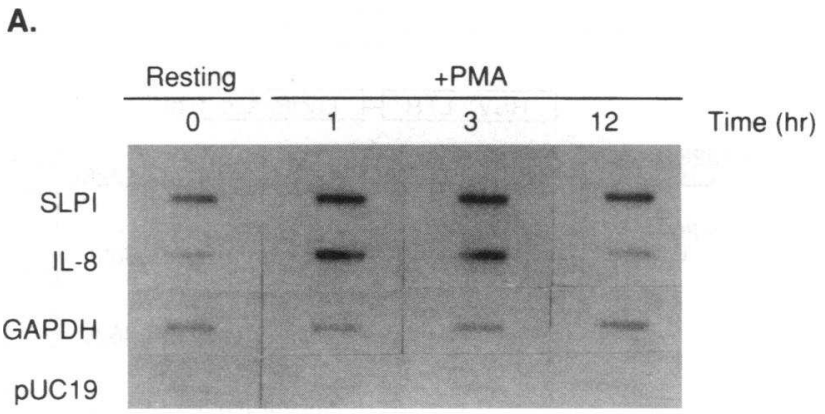

B.

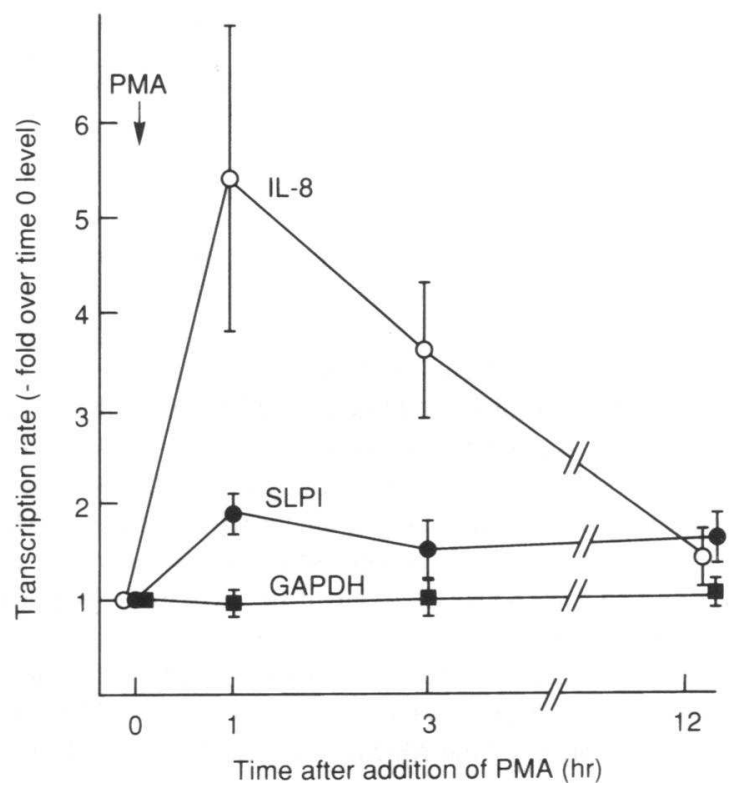

Figure 4. Effect of PMA on the transcription rate of SLPI gene in HS24 cells. The cells were incubated in the presence of PMA (100 nM) for 1,3 , and $12 \mathrm{~h} .{ }^{32} \mathrm{P}$-labeled nascent nuclear RNA was hybridized to nylon membrane-bound DNA target plasmids ( $5 \mu \mathrm{g}$ each) including SLPI, IL-8, GAPDH, and the control plasmid pUC19. ( $A$ ) Example of a representative autoradiogram of three independent experiments. $(B)$ Relative increase in the rate of SLPI $(\bullet), \mathrm{IL}-8(0)$, and GAPDH ( $\bullet)$ gene transcription expressed as the -fold increase over that of cells at time 0 .

of the SLPI gene. Evaluation of increasing lengths of 5' flanking sequence from -115 to -1228 showed no change in reporter gene expression $(P>0.1$, all comparisons $)$.

As expected, PMA gave an overall increase in relative transcription rate with all fragments from -97 to $-1,228$ compared with resting values (Fig. 6$)(P<0.05$, all comparisons). The importance of the 18-bp fragment between -98 and -115 in the level of transcription was demonstrated by the dramatic difference in reporter gene expression between plasmids pSL97L and pSL115L (Fig. 6), which differ only by these 18 


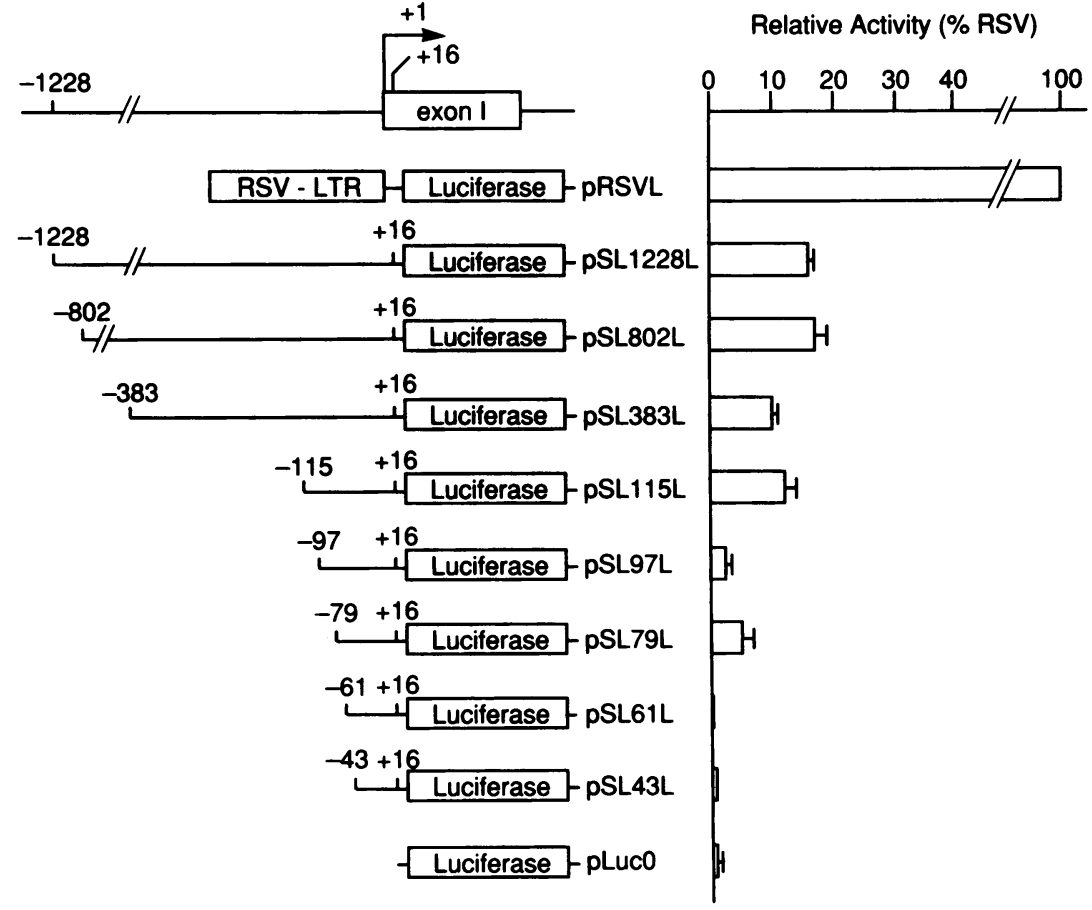

Figure 5. Promoter activity of the 5 ' flanking region of SLPI gene in HS-24 cells. Promoter activity was evaluated using fusion genes including sequentially deleted 5' flanking regions of SLPI gene and a luciferase reporter gene. Levels of luciferase expression by the fusion gene constructs are shown relative to the expression of the positive control, a fusion gene consisting of the RSV promoter and the luciferase reporter gene ( $\mathrm{pRSVL}$ ). pLuc0, a promoterless luciferase plasmid, served as the negative control. Relative values of luciferase activity were adjusted by transfection efficiency as determined by CAT expression by cotransfection of a cytomegalovirus promoter-CAT plasmid (pCMV-CAT). The data are presented as mean \pm SEM of at least three independent experiments. nucleotides, and by the significant reduction in reporter gene expression of longer constructs with this element deleted $(P$ $<0.05)$. Interestingly, this 18 -bp segment and immediate flanking regions show substantial homology with sequences in other genes demonstrated to enable PMA inducibility of expression (Fig. 7). There are two elements in this region of the SLPI promoter shared with the region of the Moloney murine leukemia virus (MoMLV) enhancer which confers PMA inducibility (38). One is a partial NFkB sequence (39), also seen in the PMA response element of the urokinase gene (40), and the other element shared with the c-fos promoter (41) and termed the serum response element. Mutation of either of these elements has been shown to markedly reduce PMA induction of transcription of the MoMLV gene (38). The IL-8 promoter also contains a partial NFkB element, and an element resembling the serum response element (in reverse orientation) that has homology with the octomer motif, in addition to C/EBP and AP-3 sites in a region critical for PMA induction (42, 43). Surprisingly, although important in the overall level of transcription, this 18-bp element in the SLPI 5 '-flanking region has not been shown to provide the inducibility of expression seen with PMA, as the shortest construct evaluated, pSL97, which does not include this element, and the longer constructs with this element deleted (pSL383LD, 802LD, and 1228LD) were also responsive to PMA.

Stability of SLPI mRNA transcripts. After the inhibition of RNA synthesis with actinomycin D, SLPI mRNA transcripts were relatively stable in HS-24 cells as reported by Abe et al.

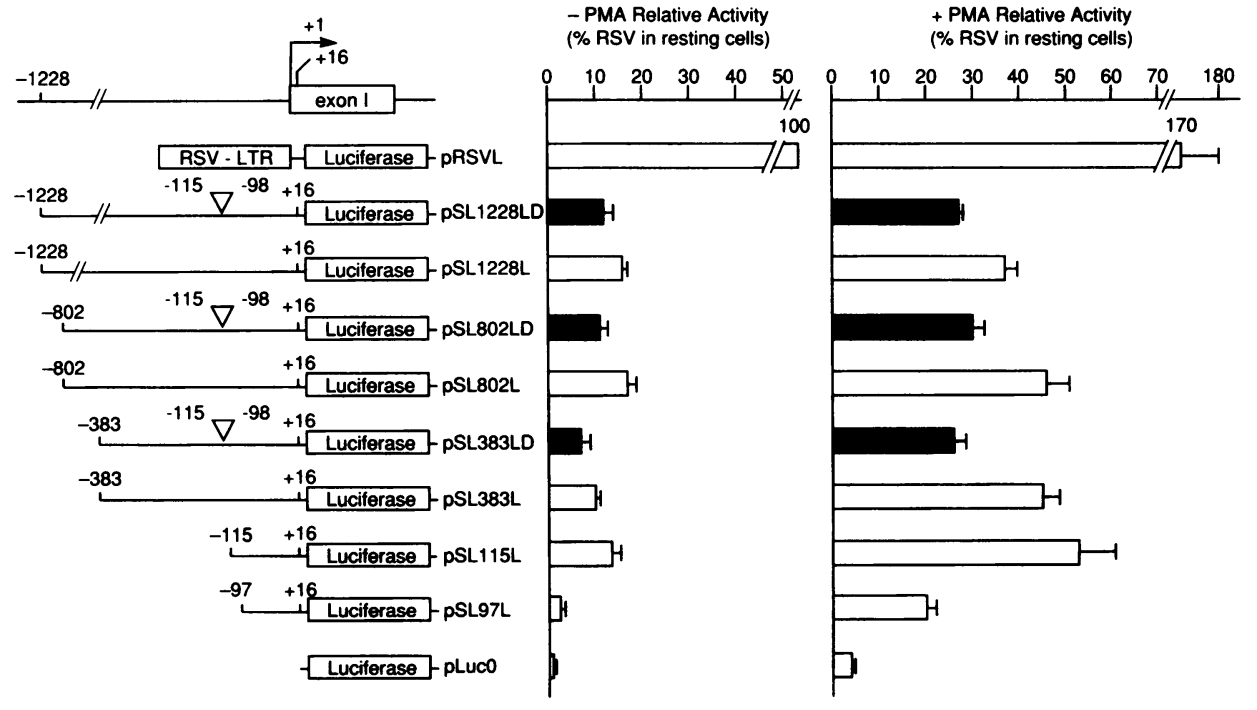

Figure 6. Promoter activity of the 5' flanking region of SLPI gene in HS24 cells after exposure of the cells to PMA. To evaluate the effect of PMA on SLPI promoter activity in HS-24 cells, the cells transfected with the fusion genes were stimulated with PMA $(100 \mathrm{nM})$ for $24 \mathrm{~h}$. At the right, the expression of each construct in the presence or absence of PMA expressed relative to the expression in resting cells of the positive control (pRSVL) is shown. Promoter activity of deletion mutants of the $5^{\prime}$ flanking region of the SLPI gene (bp -98 to -115 deleted) is also shown in resting conditions and after exposure of the cells to PMA, in comparison to the nondeleted controls. The data are presented as mean \pm SEM of at least three independent experiments. 


\begin{tabular}{|c|c|}
\hline SLPI & 5 ' -CAGGAT T TCTGOTCTCTOCCTACOTITCCTGCT TATGCAAT \\
\hline MOMLV & 5'-CAGGATA TCTGTGGTAAG . . . CAGITCCTGC \\
\hline C-fos & $5 \cdot$ - CAGGATGTCCATATT \\
\hline IL-8 & $5^{\prime}$-GC $\overline{A A A T C G T G} \ldots \ldots \ldots$ GAAITTCCT \\
\hline Urokinase & $5^{\prime}$-ACTTGTACITTCCCCAGCAGGCAGC \\
\hline NFkB & $5^{\prime}-G G G A C I T T C C$ \\
\hline
\end{tabular}

Figure 7. Comparison of the SLPI promoter to PMA responsive elements in other genes. The nucleotide sequence of the SLPI gene 5' flanking region important in the level of transcription is compared with similar sequences in the Moloney murine leukemia virus enhancer, the IL-8 gene, and the urokinase gene. The portion of the SLPI gene deleted in the promoter function experiments is shown in bold. The sequences resembling the serum response element of the c-fos gene are overlined (note in inverse orientation in IL-8 gene) and compared with the c-fos sequence. The sequences resembling the partial NFkB sequence (TTTCC) are underlined and compared with the complete NFkB sequence.

(11) (Fig. 8). Interestingly, cells preincubated with PMA (100 $\mathrm{nM}, 12 \mathrm{~h}$ ) had significantly increased SLPI mRNA levels, reaching a level of twofold above the control level at $16 \mathrm{~h}(P$ $<0.02$, PMA-preincubated cells compared with HS-24 cells alone at $16 \mathrm{~h}$ ). Thus, it appears that the upregulation of SLPI transcript levels after PMA stimulation is modulated by both increases in transcription rate and in mRNA transcript stability.

\section{Discussion}

The imbalance between proteases and protease inhibitors on the airway epithelial surface is a major pathogenic determinant in a variety of acute and chronic inflammatory lung disorders (4, 44, 45). Many of these disorders are characterized by an increased burden of neutrophils and, therefore, neutrophil elastase, a $29-\mathrm{kD}$ proteolytic enzyme, on the airway epithelial surface (44-48). If NE is allowed to remain in its active state, it is dangerous to the local milieu, as it is capable of injuring the airway epithelium, increasing local mucus production, and interfering with pulmonary host defense $(46,49,50)$. Secretory leukoprotease inhibitor, a $12-\mathrm{kD}$ nonglycosylated serine antiprotease produced by airway epithelial cells, plays a role in protecting the airway epithelium from NE (1-6). Further, the fact that SLPI is acid stable likely enables it to remain functional in the decreased $\mathrm{pH}$ vicinity of activated neutrophils (51) and

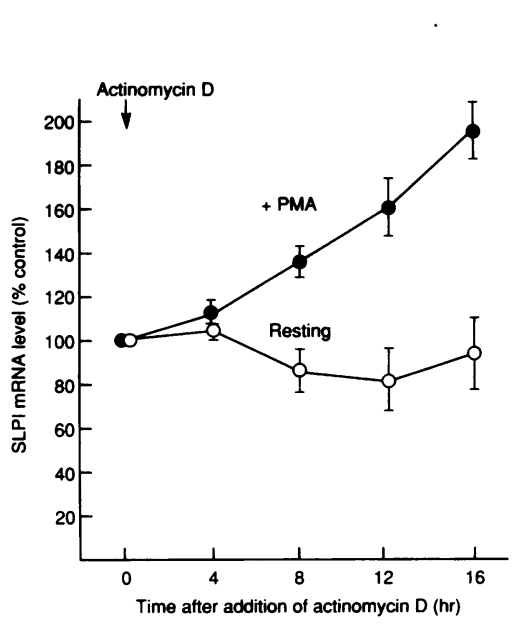

Figure 8 . Stability of SLPI mRNA transcripts in HS-24 cells. Shown are effects of inhibition of RNA synthesis on SLPI mRNA levels in resting and PMA-stimulated ( $100 \mathrm{nM}$ for $12 \mathrm{~h}$ ) HS- 24 cells. Cells were harvested at the indicated times after the addition of actinomycin D (5 $\mu \mathrm{g}$ / $\mathrm{ml}$ ) and the extracted RNA was evaluated by Northern analyses. The data are presented as mean \pm SEM of four independent experiments. to protect against proteolysis at the neutrophil substrate interface (7).

The present study demonstrates that the SLPI gene is upregulated in human airway epithelial cells by inflammatory stimuli, the increase in mRNA levels brought about by increased transcription and mRNA stability is associated with a twofold increase in secreted SLPI protein. This provides a biologic basis for the clinical observations that SLPI levels are increased in serum and respiratory epithelial lining fluid in inflammatory lung disorders (15-17). The fact that the SLPI gene can be upregulated by inflammatory stimuli is of interest in the context that the synthesis of $\alpha 1 \mathrm{AT}$, a $52-\mathrm{kD}$ serine antiprotease that also plays an important role in defending the airways from NE, is also upregulated by inflammatory stimuli $(4,20)$. In contrast to SLPI, which is produced by airway epithelial cells and secreted for local use, $\alpha 1 \mathrm{AT}$ is produced primarily in hepatocytes, secreted into the circulation, and diffuses across the respiratory tract to reach the epithelial surface $(4,52,53)$. $\alpha 1$ AT has long been known to be an acute phase reactant $(4,18,19)$. Interestingly, while SLPI gene expression in human bronchial epithelial cells can be upregulated by PMA and TNF- $\alpha$, it is not influenced by IL- $1 \beta$ or IL- 6 . In contrast, $\alpha 1$ AT synthesis in human hepatoma cells is induced by IL-6, but not by IL$1 \beta$ or TNF $(20,54)$. These observations, together with the knowledge that SLPI is produced by serous cells $(3,8)$, while $\alpha 1 \mathrm{AT}$ is produced mainly by hepatocytes $(4,52,53)$, suggest that the two major serine antiproteases responsible for protecting the lung from NE are regulated by different mechanisms.

The 5' flanking region of SLPI gene contains elements with the potential to be modulated by inflammatory stimuli, and thus it was expected that SLPI gene expression would be influenced at the transcriptional level by PMA. The data demonstrate that this is the case, with PMA significantly upregulating the transcription of the SLPI gene in human airway epithelial cells. However, there is no apparent correlation between the known position of putative PMA response elements, including AP-1 and AP-2 sites $(-812,-575$, and -470 for AP-1; -284 and -219 for AP-2; see reference 11), a region homologous with the PMA response element in the MoMLV promoter ( -93 to -124 ), and the DNA fragments of the 5 ' flanking region responsible for the upregulation observed. The exact nature of the elements important in the upregulation of transcription of the SLPI gene by PMA remains to be defined.

Phorbol esters, including PMA, not only modulate the transcription rate of a variety of genes, but also can influence the stability of mRNA transcripts of some genes, likely through signaling mechanisms involving protein kinase $C$ (55-60). Consistent with this, we observed that PMA enhanced SLPI mRNA accumulation by increasing SLPI mRNA stability. However, for most mRNA transcripts that are stabilized by PMA, such as intercellular adhesion molecule-1, granulocyte-monocyte colony stimulating factor, IL- $1 \beta$, and c- $f m s(57-60)$, the mRNAs are all short lived, and except for c- $f m s$, the $3{ }^{\prime}$ untranslated regions of these mRNAs contain multiple copies of the sequence AUUUA, which serve as a destabilizing signal (5760 ). This AUUUA motif and a protein that binds to the motif, adenosine-uridine binding factor, are thought to function as the cis-acting element and the trans-acting factor mediating PMAregulated turnover of these $m R N A s$, respectively $(58,61)$. Interestingly, the SLPI mRNA does not contain this pentamer motif in the $3^{\prime}$ untranslated region (62), suggesting there must be other motif(s) of SLPI mRNA that confer the mRNA stabil- 
ity and enhance PMA-regulated stabilization of SLPI transcripts.

The airway epithelium can produce and release a variety of inflammatory mediators, including $\mathrm{IL}-1 \beta, \mathrm{IL}-6$, and granulocyte-macrophage colony-stimulating factor $(63,64)$. Further, the airway epithelium can recruit inflammatory cells, for example by releasing IL-8, a major chemoattractant for neutrophils $(29,65)$. Importantly, as observed in the present study with the SLPI gene, the epithelium also plays an active role in defending the airways, with mechanisms regulating its defensive armamentarium against inflammation.

\section{Acknowledgments}

We thank B. Doujaiji, Pulmonary Branch, National Heart, Lung, and Blood Institute (NHLBI), for help in measuring the SLPI protein levels, and N.G. McElvaney, Pulmonary Branch, NHLBI, for helpful discussions.

\section{References}

1. Thompson, R. C., and K. Ohlsson. 1986. Isolation, properties, and complete amino acid sequence of human secretory leukocyte protease inhibitor, a potent inhibitor of leukocyte elastase. Proc. Natl. Acad. Sci. USA. 83:6692-6696.

2. Mooren, H. W. D., J. A. Kramps, C. Franken, C. J. L. M. Meijer, and J. A. Dijkman. 1983. Localisation of a low-molecular-weight bronchial protease inhibitor in the peripheral human lung. Thorax. 38:180-183.

3. Franken, C., C. J. L. M. Meijer, and J. H. Dijkman. 1989. Tissue distribution of antileukoprotease and lysozyme in humans. J. Histochem. Cytochem. 37:493498.

4. Hubbard, R. C., and R. G. Crystal. 1991. Antiproteases. In The Lung: Scientific Foundation. R. G. Crystal, J. B. West, F. Barnes, E. R. Weibel, and N. S. Cherniack, editors. Vol. 2. Raven Press, Inc., New York. 1775-1788.

5. Vogelmeier, C., R. Buhl, R. F. Hoyt, E. Wilson, G. A. Fells, R. C. Hubbard, H.-P. Schnebli, R. C. Thompson, and R. G. Crystal. 1990. Aerosolization of recombinant SLPI to augment antineutrophil elastase protection of pulmonary epithelium. J. Appl. Physiol. 69:1843-1848.

6. Gauthier, F., U. Fryksmark, K. Ohlsson, and J. G. Bieth. 1982. Kinetics of the inhibition of leukocyte elastase by the bronchial inhibitor. Biochem. Biophys. Acta. 700:178-183.

7. Rice, W. G., and S. J. Weiss. 1990. Regulation of proteolysis at the neutrophil substrate interface by secretory leukoprotease inhibitor. Science (Wash. DC). 249:178-181.

8. Fryksmark, U., K. Ohlsson, Å. Polling, and H. Tegner. 1982. Distribution of antileukoprotease in upper respiratory mucosa. Ann. Otol. Rhinol. Laryngol. 91:268-271.

9. Vogelmeier, C., R. C. Hubbard, G. A. Fells, H.-P. Schnebli, R. C. Thompson, H. Fritz, and R. G. Crystal. 1991. Anti-neutrophil elastase defense of the normal human respiratory epithelial surface provided by the secretory leukoprotease inhibitor. J. Clin. Invest. 87:482-488.

10. Smith, S. F., A. Guz, A. J. Winning, N. T. Cooke, G. H. Burton, and T. D. Tetley. 1988. Comparison of human lung surface protein profiles from the central and peripheral airways sampled using two regional lavage techniques. Eur. Respir. J. 1:792-800.

11. Abe, T., N. Kobayashi, K. Yoshimura, B. C. Trapnell, H. Kim, R. C. Hubbard, M. T. Brewer, R. C. Thompson, and R. G. Crystal. 1991. Expression of the secretory leukoprotease inhibitor gene in epithelial cells. J. Clin. Invest. 2207-2215.

12. Lee, W., P. Mitchell, and R. Tjian. 1987. Purified transcription factor AP1 interacts with TPA-inducible enhancer elements. Cell. 49:741-752.

13. Angel, P., M. Imagawa, R. Chiu, B. Stein, R. J. Imbra, H. J. Rahmsdorf, C. Jonat, P. Herrlich, and M. Karin. 1987. Phorbol ester-inducible genes contain a common cis element recognized by a TPA-modulated trans-acting factor. Cell. 49:729-739.

14. Imagawa, M., R. Chiu, and M. Karin. 1987. Transcription factor AP-2 mediates induction by two different signal-transduction pathways: protein kinase C and cAMP. Cell. 51:251-260.

15. Kida, K., T. Mizuuchi, K. Takeyama, T. Hiratsuka, S. Jinno, K. Hosoda, A. Imaizumi, and Y. Suzuki. 1992. Serum secretory leukoprotease inhibitor levels to diagnose pneumonia in the elderly. Am. Rev. Respir. Dis. 146:1426-1429.

16. Fryksmark, U., T. Prellner, H. Tegner, and K. Ohlsson. 1984. Studies on the role of antileukoprotease in respiratory tract diseases. Eur. J. Respir. Dis. 65:201-209.

17. Ohlsson, K., T. Sveger, and N. Svenningsen. 1992. Protease inhibitors in bronchoalveolar lavage fluid from neonates with special reference to secretory leukocyte protease inhibitor. Acta Paediatr. 81:757-759.

18. Aronsen, K.-F., G. Ekelund, C.-O. Kindmark, and C.-B. Laurell. 1972. Sequential changes of plasma proteins after surgical trauma. Scan. J. Clin. Lab. Invest. 29(Suppl. 124):127-136.

19. Dickson, I., and C. A. Alper. 1974. Changes in serum proteinase inhibitor levels following bone surgery. Clin. Chim. Acta. 54:381-385.

20. Perlmutter, D. H., L. T. May, and P. B. Sehgal. 1989. Interferon $\beta 2 /$ interleukin 6 modulates synthesis of $\alpha 1$-antitrypsin in human mononuclear phagocytes and in human hepatoma cells. J. Clin. Invest. 84:138-144.

21. Appelhans, B., B. Ender, G. Sachse, T. Nikiforov, H. Appelhans, and W. Ebert. 1987. Secretion of antileucoprotease from a human lung tumor cell line. FEBS (Fed. Eur. Biochem. Soc.) Lett. 224:14-18.

22. Reddel, R. R., Y. Ke, B. I. Gerwin, M. G. McMenamin, J. F. Lechner, R. T. Su, D. E. Brash, J.-B. Park, J. S. Rhim, and C. C. Harris. 1988. Transformation of human bronchial epithelial cell lines by infection with SV40 or adenovirus-12 SV40 hybrid virus, or transfection via strontium phosphate coprecipitation with a plasmid containing SV40 early region genes. Cancer Res. 48:1904-1909.

23. Ausubel, F. M., R. Brent, R. E. Kingston, O. D. Moore, J. A. Smith, J. G. Seidman, and K. Struhl. 1993. Current Protocols in Molecular Biology. John Wiley \& Sons, New York. 4.9.1-4.9.8.

24. Chirgwin, J. M., A. E. Przybyla, R. J. MacDonald, and W. J. Rutter. 1979. Isolation of biologically active ribonucleic acid from sources enriched in ribonuclease. Biochemistry. 18:5294-5299.

25. Feinberg, A. P., and B. Vogelstein. 1983. A technique for radiolabeling DNA restriction endonuclease fragments to high specific activity. Anal. Biochem. 132:6-13.

26. Ercolani, L., B. Florence, M. Denaro, and M. Alexander. 1988. Isolation and complete sequence of a functional human glyceraldehyde-3-phosphate dehydrogenase gene. J. Biol. Chem. 263:15335-15341.

27. Greenberg, M. E., and E. B. Ziff. 1984. Stimulation of 3T3 cells induces transcription of the c-fos proto-oncogene. Nature (Lond.). 311:433-438.

28. Chomczynski, P., and N. Sacchi. 1987. Single-step method of RNA isolation by acid guanidinium thiocyanate-phenol-chloroform extraction. Anal. Biochem. 162:156-159.

29. Nakamura, H., K. Yoshimura, H. A. Jaffe, and R. G. Crystal. 1991. Interleukin-8 gene expression in human bronchial epithelial cells. J. Biol. Chem. 266:19611-19617.

30. Liu, J. M., H. Fujii, S. W. Green, N. Komatsu, N. S. Young, and T. Schimada. 1991. Indiscriminate activity from the B19 parvovirus P6 promoter in nonpermissive cells. Virology. 182:361-364.

31. Deng, W. P., and J. A. Nickoloff. 1992. Site directed mutagenesis of virtually any plasmid by eliminating a unique site. Anal. Biochem. 200:81-88.

32. Sanger, F., S. Nicklen, and A. R. Coulson. 1977. DNA sequencing with chain-terminating inhibitors. Proc. Natl. Acad. Sci. USA. 74:5436-5467.

33. De Wet, J. R., K. V. Wood, M. Deluca, D. R. Helinski, and S. Subramani. 1987. Firefly luciferase gene: structure and expression in mammalian cells. Mol. Cell. Biol. 7:725-737.

34. Yoshimura K., H. Nakamura, B. C. Trapnell, W. Dalemans, A. Pavirani, J-P. Lecocq, and R. G. Crystal. 1991. The cystic fibrosis gene has a "housekeeping" -type promoter and is expressed at low levels in cells of epithelial origin. J. Biol. Chem. 266:9140-9144.

35. Potter, H., L. Weir, and P. Leder. 1984. Enhancer-dependent expression of human $\kappa$ immunoglobulin genes introduced into mouse pre-B lymphocytes by electroporation. Proc. Natl. Acad. Sci. USA. 81:7161-7165.

36. Bradford, M. M. 1976. A rapid and sensitive method for the quantitation of microgram quantities of protein utilizing the principle of protein-dye binding. Anal. Biochem. 72:248-254.

37. Gorman, C. M., L. F. Moffat, and B. H. Howard. 1982. Recombinant genomes which express chloramphenicol acetyltransferase in mammalian cells. Mol. Cell. Biol. 2:1044-1051.

38. Speck, N. A., B. Renjifo, and N. Hopkins. 1990. Point mutations in the Moloney murine leukemia virus enhancer identify a lymphoid specific viral core motif and 1,3-phorbol myristate acetate inducible element. J. Virol. 64:543-550.

39. Urban, M. B., R. Schreck, and P. A. Baaeuerle. 1991. NF-kB contacts DNA by a heterodimer of the p50 and p65 subunit. EMBO (Eur. Mol. Biol. Organ.) J. 10:1817-1825.

40. Hansen, S. K., C. Nerlov, U. Zabel, P. Verdde, M. Johnsen, P. A. Baeuerle, and F. Blasi. 1992. A novel complex between the p65 subunit of the NFkB and c-Rel binds to a DNA element involved in the phorbol ester induction of the human urokinase gene. EMBO (Eur. Mol. Biol. Organ.) J. 11:205-213.

41. Schtoter, H. P., P. E. Shaw, and A. R. Nordheim. 1987. Purification of intercalator-released p67, a polypeptide that interacts specifically with the c-fos serum response element. Nucleic Acids Res. 15:10145-10158.

42. Yasumoto, K., S. Okamoto, N. Mukaida, S. Murakami, M. Mai, and K. Matsushima. 1992. Tumor necrosis factor $\alpha$ and interferon $\gamma$ synergistically induce interleukin 8 production in a human gastric cancer cell line through acting concurrently on AP-1 and NF-kB like binding sites of the interleukin 8 gene. J. Biol. Chem. 267:22506-22511.

43. Mukaida, N., Y. Mahe, and K. Matsushima. 1990. Cooperative interaction 
of nuclear factor $\mathrm{kB}$ and cis regulatory enhancer binding pro-inflammatory cytokines. J. Biol. Chem. 205:21128-21133.

44. Hubbard, R. C., M. L. Brantly, and R. G. Crystal. 1991. Proteases. In The Lung: Scientific Foundation. R. G. Crystal, J. B. West, F. Barnes, E. R. Weibel and N. S. Sherniack, editors. Vol. 2. Raven Press, Inc., New York. 1763-1773.

45. Lucey, E. C., P. J. Stone, and G. L. Snider. 1991. Consequences of proteolytic injury. In The Lung: Scientific Foundation. R. G. Crystal, J. B. West, F. Barnes, E. R. Weibel, and N. S. Sherniack, editors. Vol. 2. Raven Press, Inc. New York. 1789-1801.

46. McElvaney, N. G., R. C. Hubbard, P. Birrer, M. S. Chernick, D. B. Caplan, M. M. Frank, and R. G. Crystal. 1991. Aerosol $\alpha 1$-antitrypsin treatment for cystic fibrosis. Lancet. 337:392-394.

47. Nakamura, H., K. Yoshimura, N. G. McElvaney, and R. G. Crystal. 1992 Neutrophil elastase in respiratory epithelial lining fluid of individuals with cystic fibrosis induces interleukin-8 gene expression in a human bronchial epithelial cell line. J. Clin. Invest. 89:1478-1484.

48. Weiss, S. J. 1989. Tissue destruction by neutrophils. N. Engl. J. Med. 320:365-376.

49. Berger, M., R. U. Sorensen, M. F. Tosi, D. G. Dearborn, and G. Döring. 1989. Complement receptor expression on neutrophils at an inflammatory site, the Pseudomonas-infected lung in cystic fibrosis. J. Clin. Invest. 84:1302-1313.

50. Tosi, M. F., H. Zakem, and M. Berger. 1990. Neutrophil elastase cleaves C3bi on opsonized Pseudomonas as well as CR1 on neutrophils to create functionally important opsonin receptor mismatch. J. Clin. Invest. 86:300-308.

51. Fritz, H. 1988. Human mucus proteinase inhibitor (human MPI): human seminal inhibitor I (HUSI-I), antileukoprotease (ALP), secretory leukoprotease inhibitor (SLPI). Biol. Chem. Hoppe-Seyler. 369:79-82.

52. Crystal, R. G. 1989. The $\alpha 1$-antitrypsin gene and its deficiency states. Trends Genetics. 5:411-417.

53. Crystal, R. G. 1990. $\alpha 1$-antitrypsin deficiency, emphysema, and liver disease: genetic basis and strategies for therapy. J. Clin. Invest. 85:1343-1352.

54. Perlmutter, D. H., C. A. Dinarello, P. I. Punsal, and H. R. Colten. 1986 Cachectin/tumor necrosis factor regulates hepatic acute-phase gene expression J. Clin. Invest. 78:1349-1354.

55. Bargon, J., B. C. Trapnell, K. Yoshimura, W. Dalemans, A. Pavirani, J.-P Lecocq, and R. G. Crystal. 1992. Expression of the cystic fibrosis transmembrane conductance regulator gene can be regulated by protein kinase C. J. Biol. Chem. 267:16056-16060

56. Lund, L. R., E. Rønne, A. L. Roldan, N. Behrendt, J. Rømer, F. Blasi, and K. Danø. 1991. Urokinase receptor mRNA level and gene transcription are strongly and rapidly increased by phorbol myristate acetate in human monocytelike U937 cells. J. Biol. Chem. 266:5177-5181.

57. Wertheimer, S. J., C. L. Myers, R. W. Wallace, and T. P. Parks. 1992. Intracellular adhesion molecule-1 gene expression in human endothelial cells: differential regulation by tumor necrosis factor- $\alpha$ and phorbol myristate acetate. J. Biol. Chem. 267:12030-12035.

58. Shaw, G., and R. Kamen. 1986. A conserved AU sequence from the 3' untranslated region of GM-CSF mRNA mediates selective mRNA degradation. Cell. 46:659-667.

59. Yamato, K., Z. El-Hajjaoui, and H. P. Koeffler. 1989. Regulation of levels of IL-1 mRNA in human fibroblasts. J. Cell. Physiol. 139:610-616.

60. Weber, B., J. Horiguchi, R. Luebbers, M. Sherman, and D. Kufe. 1989. Posttranscriptional stabilization of c- $f m s$ mRNA by a labile protein during human monocytic differentiation. Mol. Cell. Biol. 9:769-775.

61. Vakalopoulou, E., J. Schaack, and T. Shenk. 1991. A 32-kilodalton protein binds to AU-rich domains in the $3^{\prime}$ untranslated regions of rapidly degraded mRNAs. Mol. Cell. Biol. 11:3355-3364.

62. Stetler, G., M. T. Brewer, and R. C. Thompson. 1986. Isolation and sequence of a human gene coding a potent inhibitor of leukocyte proteases. Nucleic Acids Res. 14:7883-7896.

63. Mattoli, S., F. Colotta, G. Fincato, M. Mezzetti, A. Mantovani, F. Patalano, and A. Fasoli. 1991. Time course of ILI and IL6 synthesis and release in human bronchial epithelial cell cultures exposed to toluene diisocyanate. J. Cell. Physiol. 149:260-268.

64. Cromwell, O., Q. Hamid, C. J. Corrigan, J. Barkans, Q. Meng, P. D. Collins, and A. B. Kay. 1992. Expression and generation of interleukin-8, IL-6 and granulocyte-macrophage colony-stimulating factor by bronchial epithelial cells and enhancement by IL- $1 \beta$ and tumour necrosis factor- $\alpha$. Immunology. 77:330-337.

65. McElvaney, N. G., H. Nakamura, P. Birrer, C. A. Hébert, W. L. Wong, M. Alphonso, J. B. Baker, M. A. Catalano, and R. G. Crystal. 1992. Modulation of airway inflammation in cystic fibrosis: in vivo suppression of interleukin-8 levels on the respiratory epithelial surface by Aerosolization of recombinant secretory leukoprotease inhibitor. J. Clin. Invest. 90:1296-1301. 